\title{
ANALISIS PENGARUH STRES KERJA DAN ORGANIZATIONAL CITIZENSHIP BEHAVIOR TERHADAP KEPUASAN KERJA DAN DAMPAKNYA TERHADAP RETENSI KARYAWAN DI FORD JAKARTA PUSAT
}

\author{
Stefhani; Laksmi Sito Dwi Irvianti \\ Management Department, School of Business Management, BINUS University \\ Jln. K.H. Syahdan No. 9, Palmerah, Jakarta Barat 11480 \\ stefhaniphang@live.com; laksmisito@binus.ac.id
}

\begin{abstract}
Ford Jakarta Pusat is an authorized automotive dealer company. This study was conducted to determine how much influence of work stress and Organizational Citizenship Behaviour on job satisfaction and the impact on employee retention. There were 50 employees in Ford Jakarta Pusat used as research object. Data were obtained by spreading the questionnaire to the respondents using Cross Sectional Time Horizon. The data have been collected and processed using Path Analysis approach. According to the research result, it shows that work stress and Organizational Citizenship Behaviour have a simultaneous and significant effect on job satisfaction although work stress individually does not have a significant effect on job satisfaction. Then, work stress, Organizational Citizenship Behaviour, and job satisfaction have a simultaneous and significant effect on employee retention although work stress individually does not have a significant effect on employee retention. After trimming process, the result shows that Organizational Citizenship Behaviour and job satisfaction have a simultaneous and significant effect on employee retention. It means that if the company wants to maintain and improve employee retention, it must improve the Organizational Citizenship Behaviour through Job Satisfaction.
\end{abstract}

Keywords: work stress, Organizational Citizenship Behaviour, job satisfaction, employee retention, Path analysis

\begin{abstract}
ABSTRAK
Ford Jakarta Pusat merupakan sebuah perusahaan dealer resmi mobil Ford. Tujuan dari penelitian adalah untuk mengetahui seberapa besar pengaruh dari stres kerja dan Organizational Citizenship Behaviour terhadap kepuasan kerja, serta dampaknya pada retensi karyawan. Sebanyak 50 orang karyawan Ford Jakarta Pusat digunakan sebagai objek penelitian. Data diperoleh dengan menyebar kuesioner kepada responden. Data yang telah dikumpulkan kemudian diolah menggunakan pendekatan Path analysis. Berdasarkan hasil penelitian, diketahui bahwa stres kerja dan Organizational Citizenship Behaviour memberikan pengaruh secara simultan dan signifikan terhadap kepuasan karyawan walaupun secara individu stres kerja tidak memberikan pengaruh yang signifikan. Kemudian stres kerja, Organizational Citizenship Behaviour, dan kepuasan kerja karyawan di Ford Jakarta Pusat diketahui memberikan pengaruh secara simultan dan signifikan terhadap Retensi Karyawan walaupun secara individu stres kerja tidak memberikan pengaruh langsung yang signifikan. Setelah trimming, hasil menyatakan bahwa Organizational Citizenship Behaviour dan kepuasan kerja memiliki pengaruh simultan dan signifikan terhadap retensi karyawan. Sehingga jika perusahaan hendak mempertahankan dan meningkatkan retensi karyawan di dalam organisasi, perusahaan perlu meningkatkan Organizational Citizenship Behaviour melalui variabel kepuasan kerja terlebih dahulu.
\end{abstract}

Kata kunci: stres kerja, Organizational Citizenship Behaviour, kepuasan kerja, retensi karyawan, Path analysis 


\section{PENDAHULUAN}

Perekonomian di seluruh negara mengalami perubahan serta perkembangan yang sangat pesat. Hal tersebut disebabkan adanya globalisasi, khususnya bidang ekonomi dan sistem teknologi. Tantangan bagi setiap perusahaan adalah menyiapkan diri menghadapi globalisasi untuk mendapatkan keuntungan maksimal, Sekaligus meminimalkan kerugian akibat persaingan global melalui pengelolaan sumber daya manusia yang efisien dan efektif. Menurut data dari United Nation Development Program, Human Development Index pada 2010, negara Indonesia berada pada urutan ke 108 dari 169 negara. Sedangkan pada 2011 Indonesia berada pada urutan 124 dari 187 negara. Menurut kategori dalam HDI, Indonesia termasuk kategori 3, yaitu kategori medium human development (urutan 95-141) (Prameswari, 2012). Hal tersebut menunjukan bahwa pengelolaan dan pengembangan sumber daya manusia di Indonesia terbilang rendah, bahkan mengalami penurunan. Hal itu berarti perusahaan harus lebih bekerja keras dengan segala upaya mengelola dan mengembangkan sumber daya yang ada.

Tuntutan suatu organisasi untuk memperoleh, mengembangkan, dan mempertahankan sumber daya yang berkualitas makin mendesak sesuai dengan dinamika lingkungan yang selalu berubah. Karena perubahan yang begitu mendesak, sering kali karyawan tidak mampu mengejar dan menanggapi perubahan tersebut, akibatnya mereka mudah mengalami stres ketika bekerja. Menurut Luthans (2006) stres kerja merupakan suatu respons adaptif terhadap situasi eksternal yang mengakibatkan penyimpangan fisik, psikologis atau perilaku anggota organisasi. Artinya, karena mengalami stres, seorang karyawan tidak mampu menerima perubahan yang ada di depan mata, sekaligus juga tidak mampu menyelesaikan pekerjaan. Dalam sebuah organisasi karyawan dituntut untuk dapat bekerja dan berperan lebih dari yang menjadi peran dan tugas mereka (extra-role). Tentunya ketika tingkat stres kerja seorang karyawan tinggi, mereka juga tidak mampu berperan lebih untuk organisasi. Organizational Citizenship Behaviour didefinisikan sebagai suatu perilaku karyawan yang mau melakukan hal-hal di luar tugas formal mereka bagi organisasi tanpa mendapatkan imbalan lebih untuk mendukung perusahaan bertahan dalam kompetensi dan mencapai keberhasilan.

Salah satu bidang perdagangan dan industri yang mengalami peningkatan kesempatan kerja adalah industri otomotif. Ketua Penyelenggara IIMS 2012, Johnny Darmawan menyatakan bahwa saat ini industri otomotif menunjukan perkembangan yang menggembirakan. Dalam lima tahun terakhir, industri otomotif mengalami peningkatan yang signifikan dan permintaan pasar dari tahun ke tahun terus menerus menunjukan kenaikan. Pada 2012 industri otomotif kembali menorehkan pencapaiannya, hal tersebut terlihat dari angka produksi hingga juli naik sebanyak $33.5 \%$ bila dibandingkan dengan periode yang sama tahun depan (Antaranews, 2012). Saat ini industri otomotif merupakan penyumbang pajak terbesar.

Salah satu perusahaan yang bergerak di bidang otomotif adalah PT Kreasi Auto Kencana. PT Kreasi Auto Kencana merupakan authorized dealer resmi mobil Ford yang dipilih oleh FordMotor Indonesia (FMI). PT Kreasi Auto Kencana sudah memiliki lebih dari 5 cabang untuk melayani pelanggan, yang salah satunya adalah Ford Jakarta Pusat. Di dalam proses mempertahankan keunggulannya, ternyata Ford Jakarta Pusat mengalami banyak kendala dalam mengelola sumber daya manusia. Salah satunya adalah stres kerja dan penurunan tingkat retensi karyawan khususnya dari 2010-2012, dari tingkat retensi sebesar 63,25\% pada 2010 hingga mencapai 52,07\% pada 2012.

Stres kerja merupakan penghambat utama bagi peningkatan kinerja perusahaan secara keseluruhan. Hal itu terlihat dari hasil wawancara, yang mengatakan bahwa karyawan mengalami stres kerja karena faktor-faktor yang berasal dari dalam organisasi yaitu work overload, dan kurangnya kesempatan bagi karyawan untuk promosi jabatan bagi mereka yang sudah lama bekerja. Observasi yang telah dilakukan memperlihatkan bahwa fasilitas ruang tempat mereka bekerja pun kurang 
memadai. Sebanyak tiga departemen bercampur di satu lantai. Hal tersebut membuat kurangnya ruang gerak dan pemisahan privasi antardivisi. Kurang maksimalnya kinerja manajemen, seperti tidak adanya SOP (Standard Operating Procedure) membuat karyawan merasa bingung, apakah pekerjaan atau tugas yang sudah mereka kerjakan itu sudah sesuai atau belum. Hal itu membuat masing-masing karyawan akhirnya membuat standar sendiri. Data karyawan yang menyatakan tidak puas dalam bekerja sebesar 57,2\% merupakan angka yang cukup tinggi. Namun menariknya, hampir setiap tahun dealer Ford yang dipimpin oleh AK group dinobatkan sebagai The Best Ford Dealer of the Year dalam kurun waktu 2005 sampai 2008.

\section{Tinjauan Pustaka}

Berikut ini adalah hasil penelitian-penelitian terdahulu yang dianggap relevan dengan penelitian yang akan dilakukan. Penelitian oleh Paille (2011), kepuasan kerja dipahami sebagai proses mediasi stressful work memengaruhi hasil intention to leave dan citizenship behavior melalui kepuasan yang diperoleh karyawan. Juga diketahui bahwa stressful work tidak memiliki hubungan dengan OCB (Organizational Citizenhip Behaviour), dan satisfaction. Job satisfaction juga didapati memiliki pengaruh positif terhadap OCB dalam organisasi. Selanjutnya dalam penelitian, stressful work memiliki hasil pengaruh yang negatif dengan job satisfaction dan intention to leave. Job satisfaction dan OCB memiliki pengaruh negatif terhadap intention to leave dari karyawan. Selanjutnya adalah penelitian yang dilakukan oleh Triyanto dan Santosa (2009). Berdasarkan penelitian tersebut diketahui bahwa OCB secara negatif tidak memiliki pengaruh yang signikan pada turnover intention, tetapi secara positif berpengaruh secara signifikan terhadap job satisfaction.

Stres kerja merupakan sebuah kekuatan yang mendorong faktor fisik maupun psikologis di luar jangkauan stabilitas, membuat ketegangan dalam diri individu. Cooper dalam Arnold (2005:390) menyatakan enam faktor yang menyebabkan stres kerja, yaitu (1) faktor-faktor intrinsik pekerjaan, (2) peran dalam organisasi, (3) hubungan dalam pekerjaan, (4) pengembangan karier, (5) budaya dan iklim organisasi, (6) home-work interface. Lalu Organizational Citizenship Behaviour menurut Organ et al (2006) adalah perilaku yang berdasarkan kesukarelaan yang tidak dapat dipaksakan pada batasbatas pekerjaan dan tidak secara resmi menerima penghargaan namun mampu memberikan kontribusi bagi perkembangan produktivitas dan keefektifan organisasi. Tujuh dimensi utama dari OCB adalah (1) helping behaviour/altruism/courtesy, (2) organization loyalty, (3) organizational compliance, (4) sportmanship, (5) civic virtue, (6) conscientiousness, (7) self-development. Sementara itu, kepuasan kerja didefinisikan sebagai hasil dari persepsi karyawan mengenai seberapa baik pekerjaan mereka memberikan hal yang dinilai penting (Luthans, 2006). Faktor-faktor yang memengaruhi kepuasan kerja adalah (1) pekerjaan itu sendiri, (2) pembayaran, (3) promosi jabatan, (4) kondisi kerja. Kemudian, retensi karyawan menurut Mathis dan Jackson (2006) adalah upaya untuk mempertahankan karyawan di dalam organisasi. Faktor-faktor yang dapat menentukan retensi karyawan adalah (1) komponen organisasional, (2) peluang karier organisasional, (3) penghargaan, (4) rancangan tugas dan pekerjaan, (5) hubungan karyawan.

Berdasarkan latar belakang dan hasil penelitian sebelumnya, dilakukan penelitian mengenai pengaruh stres kerja dan OCB terhadap kepuasan kerja dan dampaknya terhadap retensi karyawan di Ford Jakarta Pusat. Penelitian ini sesuai dengan lingkungan industri otomotif saat ini yang dalam 5 tahun terakhir mengalami peningkatan dan kenaikan pangsa pasar yang signifikan. Meskipun demikian, tetap terjadi ketidakpuasan kerja dan tingkat retensi karyawan yang rendah, khususnya pada Ford Jakarta Pusat. 


\section{METODE}

Penelitian menggunakan jenis penelitian asosiatif untuk mencari korelasi antarvariabel. Metode penelitian dilakukan dengan survei menggunakan kuesioner yang disebarkan kepada karyawan Ford Jakarta Pusat sebagai unit yang dianalisis. Pengumpulan data tersebut dilakukan sebanyak satu kali atau cross-sectional. Pengambilan sampel dilakukan menggunakan simple random sampling, yaitu cara pengambilan sampel dengan setiap elemen populasi memiliki peluang yang sama untuk dijadikan anggota sampel (Sarjono \& Julianita, 2011). Dalam hal ini, populasi karyawan di Ford Jakarta Pusat diketahui sebanyak 122 orang. Untuk mengetahui jumlah sampel, penelitian menggunakan rumus Slovin. Dari rumus tersebut diperoleh jumlah sampel yang harus diambil adalah sebanyak 50 responden.

Kemudian, teknik analisis yang digunakan adalah analisis jalur (path analysis) untuk mengetahui pola hubungan dan peran langsung maupun tidak langsung dari seperangkat variabel independent terhadap variabel dependent. Data ordinal yang diperoleh melalui penyebaran kuesioner yang terlebih dahulu dilakukan transformasi menjadi data interval menggunakan metode MSI (method of successive interval). Lalu dilakukan langkah-langka sebagai berikut: uji validitas, untuk mengetahui valid (sah) atau tidaknya suatu kuesioner; uji reliabilitas, untuk mengukur keandalan suatu kuesioner; uji Normalitas, untuk mengetahui apakah data berdistribusi normal atau tidak; analisis korelasi, untuk menganalisis kuat atau lemahnya suatu variabel yang diteliti; analisis jalur. Hasil penelitian diharapkan dapat digunakan perusahaan untuk mengevaluasi dan melakukan perbaikan terhadap kepuasan kerja dan retensi karyawan di perusahaan agar dapat meningkatkan pengelolaan sumber daya manusia dengan lebih baik.

\section{HASIL DAN PEMBAHASAN}

Berikut ini adalah hasil interpretasi statistik deskriptif dari variabel Stres Kerja (X1), Organizational Citizenship Behaviour (X2), Kepuasan Kerja (Y), dan Retensi Karyawan (Z) setelah dilakukan pengujian validitas, reliabilitas, normalitas, kemudian analisis korelasi dan analisis jalur. Interpretasi statistik deskriptif diawali dengan pembuatan kriteria mengenai arti nilai masing-masing variabel tersebut. Untuk membuat kriteria, terlebih dahulu ditentukan jumlah kelas sebanyak 5 kelas. Lima kelas terdiri dari kelas pertama "sangat tidak baik", kelas kedua "tidak baik”, kelas ketiga "cukup baik”, kelas keempat "baik”, kelas kelima "sangat baik".

Selanjutnya rumus Sturges digunakan untuk lebar kelas, yaitu Jumlah Kelas (Xmax - Xmin). Penghitungan dilakukan dengan menggunakan nilai baru dengan skala interval dari variabel X1, X2, Y, dan Z. Berikut ini adalah hasil penghitungan dan interpretasi nilai dari semua variabel:

Tabel 1 Hasil Interpretasi Nilai Variabel X1, X2, Y, dan Z

\begin{tabular}{lcl}
\hline \multicolumn{1}{c}{ Variabel } & Nilai mean & \multicolumn{1}{c}{ Penilaian } \\
\hline Stres Kerja(X1) & 2,80 & Cukup Baik \\
Organizational Citizenship Behaviour (X2) & 3,17 & Baik \\
Kepuasan Kerja(Y) & 3,12 & Baik \\
Retensi Karyawan (Z) & 3,53 & Baik \\
\hline
\end{tabular}

(Sumber: Hasil Pengolahan Data, 2013) 
Analisis secara simultan menunjukkan hasil sebagai berikut. Pertama, substruktur 1, stres kerja dan Organizational Citizenship Behaviour terhadap kepuasan kerja. Kepuasan Karyawan (Y) dipengaruhi oleh stres kerja (X1) dan Organizational Citizenship Behaviour (X2) secara simultan dan signifikan sebesar 76,2\%. Sisanya sebesar 23,8\% dipengaruhi oleh variabel lain di luar penelitian. Kedua, substruktur 2 (stres kerja, Organizational Citizenship Behaviour, dan kepuasan kerja terhadap retensi karyawan). Retensi karyawan (Z) dipengaruhi stres kerja (X1) dan Organizational Citizenship Behaviour (X2), kepuasan kerja (Y) secara simultan dan signifikan sebesar 77,2\%. Sisanya sebesar $22,8 \%$ dipengaruhi variabel lain di luar penelitian.

Kemudian berdasarkan analisis jalur yang dilakukan terhadap variabel stres kerja (X1), Organizational Citizenship Behaviour(X2), dan kepuasan kerja (Y) terhadap retensi karyawan (Z) diperoleh hasil sebagai berikut:

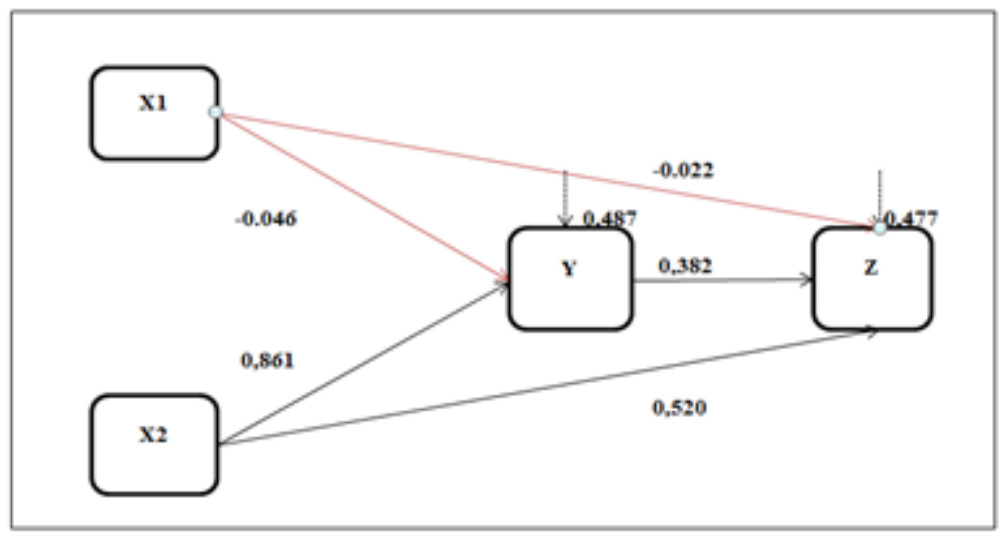

Gambar 1 Diagram Jalur Keseluruhan

(Sumber: Hasil Analisis Data, 2013)

Gambar 1 menunjukkan bahwa variabel X1 tidak signifikan terhadap Y dan Z, sehingga perlu dilakukan trimming dengan mengeluarkan variabel stres kerja (X1) yang tidak memiliki pengaruh signifikan. Lalu pengujian kembali dilakukan, yaitu variabel Organizational Citizenship Behaviour (X2), kepuasan kerja (Y) dan retensi karyawan (Z) secara parsial maupun simultan.

Setelah trimming dilakukan, diperoleh hasil analisis setiap substruktur sebagai berikut. Substruktur 1, Organizational Citizenship Behaviour terhadap kepuasan kerja, kepuasan erja (Y) dipengaruhi oleh Organizational Citizenship Behaviour (X2) secara sebesar 76\%. Kemudian sisanya sebesar 49\% dipengaruhi variabel lain di luar penelitian. Substruktur 2, Organizational Citizenship Behaviour dan kepuasan kerja terhadap retensi karyawan, pengaruh Organizational Citizenship Behaviour (X2) dan kepuasan kerja (Y) terhadap retensi karyawan secara simultan sebesar 77,1\%. Sementara kontribusi sisanya sebesar 22,9\% dimiliki oleh variabel lain di luar penelitian. Jadi hasil trimming dari keseluruhan pengaruh secara parsial dan simultan kausal variabel Organizational Citizenship Behaviour (X2) terhadap kepuasan kerja (Y) dan dampaknya terhadap retensi karyawan (Z) digambarkan dalam model struktur lengkap sebagai berikut (Gambar 2). 


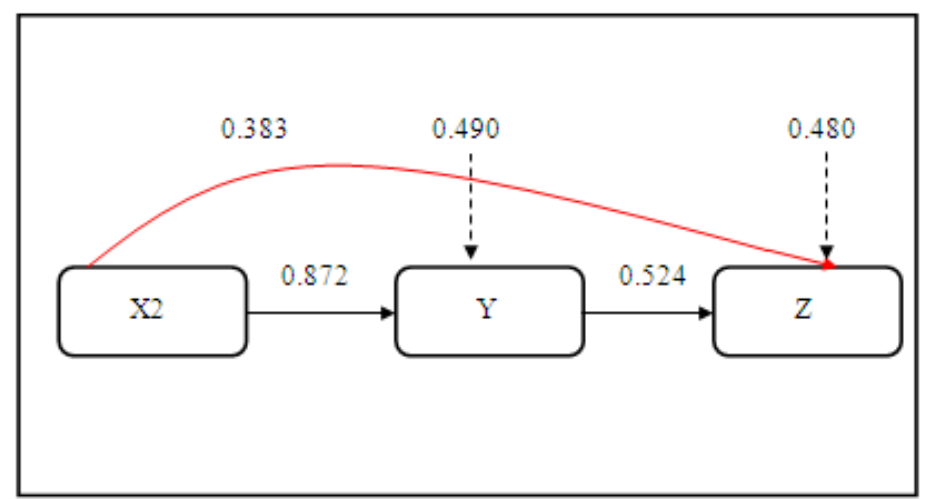

Gambar 2 Hasil Trimming Hubungan Kausal Empiris Variabel X1 dan Y terhadap Z

(Sumber: Hasil Analisis Data, 2013)

Kemudian seluruh koefisien jalur dari hubungan kasual dapat diketahui Pengaruh Kausal Langsung (PKL), Pengaruh Kausal Tidak Langsung (PKTL), dan Pengaruh Kausal Total (PKT) dari tiap variabel. Hasil disajikan dalam Tabel 2 berikut.

Tabel 2 Rangkuman Hubungan Kausal Empiris Variabel X2 dan Y terhadap Z

\begin{tabular}{lccc}
\multicolumn{1}{c}{ Pengaruh } & \multicolumn{2}{c}{ Pengaruh Kausal } & Pengaruh \\
\cline { 2 - 3 } Variabel & Langsung & Tidak Langsung & Bersama \\
\hline X2 terhadap Y & 0,872 & - & - \\
X2 terhadap Z & 0,383 & $0,872 \times 0,524=0,456$ & 0,839 \\
Y terhadap Z & 0,524 & - & - \\
X2 dan Y & - & - & 0,771 \\
terhadap Z & & - & \\
$\varepsilon_{1}$ & 0,490 & - & - \\
$\varepsilon_{2}$ & 0,480 & - & - \\
\hline
\end{tabular}

(Sumber: Hasil Analisis Data, 2013)

Berdasarkan Tabel 2, maka dapat disimpulkan hasil analisis jalur sebagai berikut. Jika Organizational Citizenship Behaviour berkontribusi secara langsung terhadap retensi karyawan hasilnya sebesar 0.383, yaitu lebih kecil. Jika dibandingkan dengan Organizational Citizenship Behaviour berkontribusi secara tidak langsung, yakni melalui kepuasan kerja sehingga kontribusi lebih besar, yaitu sebesar 0.456. Dengan demikian pengaruh Organizational Citizenship Behaviour secara tidak langsung lebih efektif diperhatikan oleh perusahaan, karena dapat memperbesar retensi karyawan.

Kemudian, hasil pembuktian hipotesis diperoleh sebagai berikut. Hipotesis pertama: pengaruh Organizational Citizenship Behaviour (X2) secara signifikan terhadap kepuasan kerja (Y) pada Ford Jakarta Pusat secara keseluruhan dinyatakan signifikan. Demikian pula secara individual semua subvariabel diterima. Berdasarkan pengujian koefisien jalur substruktur 1, koefisien jalur variabel X2 terhadap Y secara statistik adalah signifikan. Hipotesis kedua: Organizational Citizenship Behaviour (X2) dan kepuasan kerja (Y) berkontribusi secara signifikan terhadap retensi karyawan (Z) pada Ford Jakarta Pusat secara keseluruhan dinyatakan signifikan. Demikian pula secara parsial semua subvariabel diterima. Berdasarkan pengujian jalur substruktur 2, koefisien jalur X2 terhadap Z (Organizational Citizenship Behaviour terhadap retensi karyawan) signifikan; dan koefisien jalur Y terhadap Z (Kepuasan Kerja terhadap Retensi Karyawan) secara statistik signifikan. 
Setelah semua data dikumpulkan dan hasil analisis selesai dilakukan. Berikut implikasi hasil penelitian berdasarkan hasil kuesioner dengan penilaian karyawan mengenai variabel stres kerja yang ada di perusahaan dinilai "Cukup Baik". Pada Variabel Organizational Citizenship Behaviour, kepuasan kerja karyawan, retensi karyawan di Ford Jakarta Pusat dinilai "Baik” dengan jawaban yang cenderung seragam. Selanjutnya, setelah hasil kuesioner selesai dianalisis dengan analisis jalur, diperoleh hasil sebagai berikut.

Walaupun pengaruh stres kerja terhadap kepuasan kerja dan terhadap retensi karyawan tidak berpengaruh secara signifikan, dan setelah metode trimming dilakukan, variabel stres kerja dihilangkan, menurut hasil kuesioner para karyawan cenderung mengalami stres kerja. Hal itu terbukti dengan adanya hasil mean yang rendah. Hasil mean yang rendah menunjukkan bahwa pada masa yang akan datang belum tentu variabel stres kerja tidak berpengaruh pada kepuasan kerja dan retensi karyawan.

Hasil kuesioner penilaian karyawan mengenai variabel stres kerja yang ada di perusahaan dinilai “Cukup Baik” dan jawaban responden cenderung seragam. Hal ini berarti bahwa para karyawan mengalami stres yang cukup mengganggu proses mereka dalam bekerja sehingga tingkat stres mereka perlu diminimalkan. Berdasarkan hasil kuesioner, skor rendah ada pada indikator work overload. Hal itu disebabkan tingkat turnover rate di Ford Jakarta Pusat terbilang cukup tinggi. Hal tersebut dikatakan pada bagian pendahuluan bahwa tingkat turnover tiap tahun makin bertambah. Karena adanya turnover tersebut, secara otomatis, kekosongan jabatan untuk beberapa saat sering kali terjadi. Berikutnya pada indikator pengembangan karier, karyawan menilai perusahaan kurang memberikan kesempatan promosi yang adil kepada setiap karyawan. Mereka merasa secara garis besar, perusahaan memberikan promosi jabatan hanya kepada orang-orang tertentu dan bukan berdasarkan hasil penilaian prestasi karyawan. Penilaian karyawan terhadap atasan terbilang cukup baik. Mereka memiliki hubungan yang baik dengan atasan. Mereka menilai bahwa atasan sering memberikan feedback maupun saran-saran atas hasil kerja karyawan. Para atasan biasanya terjun langsung menghadapi problema para karyawan dan didiskusikan pada saat itu juga. Para atasan tentunya memiliki hubungan baik dengan para bawahannya. Setiap ada kesalahan dalam pekerjaan, atasan selalu memberikan solusi yang cocok untuk menyelesaikan masalah tersebut.

Variabel Organizational Citizenship Behaviour di Ford Jakarta Pusat dinilai “Baik” dengan jawaban yang cenderung seragam dari para karyawan. Hal ini menunjukkan bahwa perilaku yang berdasarkan kesukarelaan yang tidak dapat dipaksakan pada batas-batas pekerjaan dan tidak secara resmi menerima penghargaan namun mampu memberikan kontribusi bagi perkembangan produktivitas dan keefektifan organisasi sudah dilakukan dan ditunjukkan dengan baik oleh para karyawan. Menurut hasil kuesioner, indikator toleransi karyawan terhadap situasi yang kurang ideal di perusahaan terbilang rendah. Hal tersebut menandakan sebagian karyawan kurang loyal dan berkomitmen terhadap perusahaan. Karyawan yang memiliki komitmen dan loyalitas yang tinggi akan ikut alur proses jalannya organisasi. Ketika terjadi sesuatu yang membuat proses kerja organisasi menjadi kurang ideal, mereka seharusnya tetap berkomitmen berkontribusi pada perusahaan. Namun pada kenyataannya, mereka cenderung menghindari situasi itu dan memutuskan untuk tidak ikut campur dalam masalah perusahaan. Para karyawan diketahui dapat mengikuti dan menerima perubahan yang terjadi di dalam organisasi. Namun begitu, menerima perubahan bukan hal mudah bagi mereka. Sudah beberapa tahun ini perhitungan manual ditinggalkan Ford Jakarta Pusat. Perusahaan belum lama ini menggunakan sistem SAP agar seluruh data perusahaan dapat terbaca oleh seluruh divisi secara online. Akan tetapi, pentingnya sistem ini kurang diperhatikan. Sering kali karyawan merasa sistem SAP justru menghambat selesainya pekerjaan mereka karena jaringan internet yang kurang memadai yang menyebabkan koneksi selalu terputus. Beberapa karyawan memiliki modem sendiri sebagai cadangan jika koneksi terputus. Hal itu juga tidak bisa menyelesaikan masalah sementara banyak karyawan yang tidak memiliki modem. 
Terkait kepuasan kerja, karyawan merasa puas terhadap kerja mereka dan dikategorikan "Baik" dengan jawaban yang cenderung seragam. Kepuasan kerja yang baik ini membuat karyawan berharap akan adanya kelanjutan pekerjaan dengan organisasi. Salah satu alasan mereka puas dengan perusahaan adalah jam kerja di perusahaan. Menurut mereka perusahaan memberikan jam kerja yang sangat fleksibel dan nyaman, jika tidak ada meeting. Jika ada meeting, karyawan bisa jadi pulang malam sementara jarak rumah mereka jauh dari kantor. Hal tersebut sangat membebani mereka. Jadwal meeting di perusahaan terlihat kurang terorganisasi dengan baik. Mereka juga puas karena selama mereka bekerja mereka dapat menggunakan keterampilan dan kemampuan yang mereka miliki. Hal tersebut disebabkan sebagian besar responden berasal dari bagian marketing. Ketika mereka memasarkan produk, mereka bisa menggunakan kreativitas apapun untuk menarik pelanggan. Sedangkan responden selain divisi marketing, mereka masih bisa mengerjakan tugas mereka sesuai dengan keahlian yang mereka punya serta berdasarkan latar belakang pendidikan mereka. Skor terendah pada variabel ini adalah pada indikator kenyaman ruang kerja. Salah satu hal yang membuat mereka tidak nyaman bekerja adalah ruang kerja mereka yang tidak nyaman. Menurut mereka, ruang kerja di dalam perusahaan kurang memadai, sempit, serta tidak ada ruang gerak lebih antara ruangan dari satu divisi dengan divisi lain. Selain itu, dalam satu lantai sebanyak tiga divisi berada di lantai yang sama dengan ruangan yang tidak besar. Informasi yang didapatkan bahwa perusahaan hanya memiliki budget untuk memperluas bagian gedung yaitu ruangan display produk dan ruangan gudang serta bengkel. Perusahaan sekarang sedang melakukan renovasi ruangan display produk, bengkel, dan gudang. Sementara lantai dua tidak direnovasi. Hal tersebut terjadi karena owner lebih memfokuskan dana mereka untuk merenovasi ruangan-ruangan tadi.

Sehubungan dengan retensi karyawan, karyawan dapat bertahan di perusahaan dengan kategori penilaian "Baik" dengan jawaban mereka yang juga cenderung seragam. Hal yang membuat mereka bertahan di dalam perusahaan adalah perusahaan memberikan insentif, tunjangan yang layak seperti kesehatan kepada setiap karyawan. Hal itu membuat karyawan betah berada di perusahaan apalagi di samping gaji pokok, insentif, bonus, dan tunjangan yang memadai dapat memotivasi karyawan agar karyawan dapat terus berkomitmen serta loyal kepada perusahaan. Sementara yang masih dirasakan rendah dalam unsur retensi karyawan adalah kondisi kerja. Karyawan menilai ruangan kerja mereka kurang memadai. Telah dijelaskan sebelumnya bahwa ruang kerja sangat sempit, dan suhu udara yang panas membuat karyawan kurang nyaman bekerja. Kegaduhan yang ditimbulkan karena gabungan tiga divisi di satu lantai membuat para karyawan kurang bisa berkonsentrasi dan fokus dalam melakukan pekerjaan mereka.

\section{SIMPULAN}

Sesuai tujuan, penelitian dilakukan untuk mengetahui besar pengaruh stres kerja dan Organizational Citizenship Behaviour terhadap kepuasan kerja dan dampaknya terhadap retensi karyawan di Ford Jakarta Pusat secara simultan maupun parsial. Berdasarkan hasil yang dijabarkan, secara simultan kepuasan karyawan dipengaruhi oleh stres kerja dan Organizational Citizenship Behaviour secara simultan dan signifikan. Serta diperoleh hasil bahwa retensi karyawan dipengaruhi oleh stres kerja dan Organizational Citizenship Behaviour, kepuasan kerja secara simultan dan signifikan. Namun secara individual diperoleh hasil bahwa stres kerja tidak berkontribusi secara signifikan terhadap kepuasan kerja dan retensi karyawan dalam penelitian ini. Sementara Organizational Citizenship Behaviour menunjukkan hasil yang positif dan signifikan terhadap kepuasan karyawan dan retensi karyawan, begitu juga dengan kepuasan karyawan terhadap retensi karyawan.

Berdasarkan hasil penelitian, beberapa saran dapat diberikan untuk memperbaiki variabel yang diteliti bagi kemajuan perusahaan. Pertama, perusahaan perlu memperbaiki proses seleksi karyawan. 
Hal tersebut diperlukan untuk mengatasi tugas yang terlalu overload karena sering terjadi kekosongan jabatan di dalam perusahaan sehingga karyawan divisi yang sama harus menanggung tanggung jawab lain. Karyawan yang diseleksi harus sesuai dengan standar perusahaan, tidak kurang dari persyaratan minimum namun akan sangat baik jika lebih dari persyaratan yang ada. Karyawan yang baik adalah karyawan yang mampu bertahan di setiap kondisi perusahaan serta loyal dan berkomitmen terhadap perusahaan. Perusahaan juga harus memiliki manajemen karier agar karyawan dapat memiliki pandangan bahwa posisi mereka tidak berhenti di jabatan mereka sekarang. Sehingga dengan adanya peningkatan jenjang karier, karyawan akan lebih terpacu untuk terus berkontribusi dan loyal kepada perusahaan, dan karier mereka dapat naik. Kedua, untuk permasalahan kurangnya promosi jabatan, perusahaan hendaknya dalam beberapa periode tertentu melaksanakan kegiatan performance appraisal. Kegiatan tersebut diadakan dengan tujuan agar pihak manajemen dan karyawan itu sendiri mengetahui dengan jelas seperti apakah hasil kerja dan performa karyawan selama ini. Promosi jabatan hendaknya bisa diinformasikan kepada karyawan terkait, dan secara terbuka kepada seluruh divisi yang bersangkutan. Ketiga, untuk menyelesaikan masalah sistem dengan jaringan yang kurang baik, perusahaan hendaknya mempersiapkan dana lebih untuk memasang jaringan internet yang lebih lancar. Karena sistem merupakan jaringan yang terintegrasi dan memerlukan jaringan internet, tentunya internet harus kencang dan stabil. Perusahaan harus menggunakan jasa IT agar setiap ada masalah mengenai sistem, perusahaan bisa mengantisipasinya. Karena SAP merupakan salah satu hal yang penting bagi keberlangsungan proses kerja perusahaan, hendaknya jangan sampai menghambat karyawan dalam bekerja, di samping rugi waktu dan uang. Keempat, agar karyawan merasa nyaman dengan ruangan kerja mereka, sebaiknya perusahaan memberikan space antardivisi agar privasi dan ruang gerak mereka bisa menjadi lebih luas. Menurut observasi, arsip-arsip yang sangat banyak disimpan berbarengan dengan ruang kerja yang sempit, lebih baik perusahaan menyediakan ruang khusus arsip, supaya arsip-arsip tersusun dan tertata dengan rapi, sehingga mudah dicari. Meja-meja kerja juga bisa lebih ditata sehingga meja itu tidak terlalu dempet dan sempit tanpa pembatas namun sesama karyawan masih bisa saling berkomunikasi.

\section{DAFTAR PUSTAKA}

Antaranews. (2012, 22 September). IIMS 2012 yang Terbesar, Diikuti 310 Perusahaan. Suryanto (Ed.). Diakses dari http://otomotif.antaranews.com/berita/334671/iims-2012-yang-terbesardiikuti-310-perusahaan.

Arnold, J., et al. (2005). Work Psychology: Understanding Human Behaviour in the Workplace. $\left(4^{\text {th }}\right.$ Edition). USA: Prentice Hall.

Luthans, F. (2006). Perilaku Organisasi. (Edisi ke-10). Yogyakarta: ANDI.

Mathis, R. L., \& Jackson, J. H. (2006). Human Resource Management. (Edisi ke-10). Ohio: South Western - Thomson Learning.

Organ, D. W., Podsakof, P. M., \& MacKenzie, S. B. (2006). Organizational Citizenship Behavior: Its Nature, Antecedents, and Consequences. SAGE Publication.

Paille, P. (2011). Stressful work, citizenship behaviour and intention to leave the organization in a high turnover environment: examining the mediating role of job satisfaction. Journal of Management Research, 3(1), 1-14. 
Prameswari, D. (2012, 27 Maret). Indonesia Negara Payah Menurut HDI Index 2011. Diakses dari http://luar-negeri.kompasiana.com/2012/03/27/indonesia-negara-payah-menurut-hdi-index2011-450150.html

Sarjono, H., \& Julianita, W. (2011). SPSS vs LISREL: Sebuah Pengantar, Aplikasi Untuk Riset. Jakarta: Salemba Empat.

Triyanto \& Santosa. (2009). Organizational Citizenship Behavior (OCB) dan pengaruhnya terhadap keinginan keluar dan kepuasan kerja karyawan. Jurnal Manajemen, 7(4), 1-13. 